\title{
Recent warming trend in the coastal region of Qatar
}

\author{
Way Lee Cheng ${ }^{1} \cdot$ Ayman Saleem $^{1} \cdot$ Reza Sadr $^{1}$
}

Received: 25 May 2015 / Accepted: 28 November 2015 / Published online: 17 December 2015

(C) The Author(s) 2015. This article is published with open access at Springerlink.com

\begin{abstract}
The objective of this study was to analyze longterm temperature-related phenomena in the eastern portion of the Middle East, focusing on the coastal region of Qatar. Extreme temperature indices were examined, which were defined by the Expert Team on Climate Change Detection and Indices, for Doha, Qatar; these indices were then compared with those from neighboring countries. The trends were calculated for a 30-year period (1983-2012), using hourly data obtained from the National Climatic Data Center. The results showed spatially consistent warming trends throughout the region. For Doha, 11 of the 12 indices studied showed significant warming trends. In particular, the warming trends were represented by an increase in the number of warm days and nights and a decrease in the number of cool nights and days. The high-temperature extremes during the night have risen at more than twice the rate of their corresponding daytime extremes. The intensity and frequency of hot days have increased, and the minimum temperature indices exhibited a higher rate of warming. The climatic changes in Doha are consistent with the region-wide heat-up in recent decades across the Middle East. However, the rapid economic expansion, increase of population since the 1990s, and urban effects in the region are thought to have intensified the rapidly warming climate pattern observed in Doha since the turn of the century.
\end{abstract}

Reza Sadr

reza.sadr@qatar.tamu.edu

1 Micro Scale Thermo-Fluid Lab (MSTF), Department of Mechanical Engineering, Texas A\&M University at Qatar, Doha, Qatar

\section{Introduction}

The Earth has undergone periods of climatic change throughout its history. Before the dawn of the Industrial Revolution, climatic change was caused by natural effects, e.g., volcanic eruptions and fluctuations in solar radiation. However, global warming during the latter half of the twentieth century has accelerated and become more severe because of human activities (Zwiers et al. 2011), rapid economic expansion, and urbanization (Avila et al. 2012). In particular, because of the increase in concentrations of greenhouse gases, such as carbon dioxide (Karl et al. 2008; Jones et al. 2005), the global average temperature has risen by $0.74{ }^{\circ} \mathrm{C}$ over the last 100 years, with accelerated warming during the last three decades (Solomon et al. 2007). Another study has found that the global temperature has risen twice as fast during the first decade of the twenty-first century, compared with the final two decades of the twentieth century (Hansen et al. 2010). The increase in global mean temperature appears related to changes in the temperature extremes (Easterling et al. 1997) reported in many regions in the world. Because these extremes are located within the tails of the temperature distribution, small changes in the mean value produce large changes in the extreme temperatures (Karl et al. 2008; Trenberth 2012). A recent study concluded that the effect of hot temperature extremes has greater significance on extreme events than the global mean temperature (Seneviratne et al. 2014).

Studies have shown that, compared with the average climate, extreme events are more likely to drive changes in natural ecosystems (Parmesan et al. 2000). Such events have direct, immediate effects both on human socioeconomic structure and on natural systems. For example, extreme events such as droughts and heat waves can have serious implications for human health, harm cattle, and lead to devastated crop production and water scarcity. Such extreme events are likely to 
increase in frequency and severity (Coumou and Rahmstorf 2012) because of the warming of the Earth (Trenberth 2012). Fischer and Schär (2010) projected more intense heat waves across Europe by the end of the twenty-first century. Prolonged heat exposure could pose a major challenge to society coping with the effects of climate change, because heat waves can be a major public health hazard (Karl et al. 2008). Warming weather and urban effects are known to both worsen the problem of heat-related illness in USA (Luber and McGeehin 2008). Risk management steps to counteract the effects related to extreme climatic events, such as reduced crop production, water scarcity, and public health hazards are contingent on accurate predictions of the changing weather patterns.

The results from an analysis of global extremes (Frich et al. 2002) for the latter half of the twentieth century indicated that the world is becoming warmer; e.g., the number of cold temperature extremes decreased during that time. Analysis of global extreme temperatures in the twentieth century (specifically, 1951-2003) showed a significant increase in the annual frequency of warm nights and a reduction in the annual frequency of cold nights (Alexander et al. 2006; Morak et al. 2013). To provide a better picture of the global weather change, a number of studies have investigated extreme events in regions that have previously not been analyzed because of the lack of proper data (Peterson and Manton 2008), such as South and Central Asia, China, and South America (Frich et al. 2002; Zhai and Pan 2003; Vincent et al. 2005; Klein Tank et al. 2006).

Several studies have considered the Middle East, where reliable and high-quality weather data are available. Zhang et al. (2005) conducted the first analysis of the region for the period 1950-2003. They analyzed data from 52 stations and concluded that there were statistically significant warming trends in the Arabian Peninsula. Focusing on the Arabian Peninsula, trends of the mean, maximum, and minimum temperatures and the diurnal temperature range were found to indicate a general warming trend for most stations (AlSarmi and Washington 2011). Extreme climate indices were analyzed for some countries in the Arabian Peninsula by AlSarmi and Washington (2014). Recently, a comprehensive analysis of climate extremes, based on the 27 Expert Team on Climate Change Detection and Indices (ETCCDI) for the entire Arabian region, indicated a consistent warming trend with an increase in the occurrence of warm days and nights, fewer cold days and nights, shorter cold spells, and higher extreme temperature values (Donat et al. 2013). In a recent analysis, Lelieveld et al. (2012) concluded that the heating across the region of the eastern Mediterranean to the Arabian Peninsula is more prominent. Summer temperature in the region are expected to rise by up to $10{ }^{\circ} \mathrm{C}$, coupled with prolonged heat waves in selected population centers (Lelieveld et al. 2014). The projected significant increase in the temperature is mostly attributed to increasing air pollution, the urban heat island effect, and rapid municipal expansion, which are expected to create localized hot spots within this region. Most of these studies have focused on individual countries within the Middle East; e.g., Saudi Arabia (Almazroui et al. 2014; Islam et al. 2014), Iran (Rahimzadeh et al. 2009; Marofi et al. 2011), and Kuwait (Nasrallah et al. 2004). Nevertheless, there remains a lack of reliable, high-quality data for the analysis of climatic change in many parts of the world (Coumou and Rahmstorf 2012).

The Persian Gulf is important because of its unique geographical and weather conditions. Most studies of the climatic conditions of this region have focused on the inland areas of bigger countries such as Saudi Arabia and Iran (Almazroui et al. 2012, 2014; Rahimzadeh et al. 2009), and there have been few studies on the climatic conditions of other countries such as Bahrain and Qatar (Brooks and Rogers 2000; Shi et al. 2004). Moreover, these studies have focused mainly on interannual variations of weather, with only very limited consideration of seasonal variations, e.g., Islam et al. (2014) for Saudi Arabia and Kostopoulou et al. (2014) for the entire eastern Mediterranean and Middle East region.

The objectives of this study were to fill the gap in the analysis of climatic change within this region and to provide further insight into local weather conditions, as part of a greater effort toward the analysis of the changing weather patterns in Qatar (Singha and Sadr 2012). Data from three weather stations were used to obtain greater spatial coverage for Qatar, gain a deeper understanding of the local climate, and supplement the long-term climate change analysis of extreme temperature events in the Middle East. This paper presents a detailed analysis of the trends of extreme temperature events in Qatar based on 12 selected ETCCDI using updated weather data. The obtained trends are discussed with respect to the trends in pollution generation due to the rapid urbanization/ industrial growth of Qatar.

\section{Data}

Qatar is a peninsula located on the eastern coast of the Arabian Peninsula. It is bordered by the Kingdom of Saudi Arabia to the south and surrounded by the Persian Gulf in all other directions. The peninsula has an area of $11,571 \mathrm{~km}^{2}$, and it protrudes approximately $160 \mathrm{~km}$ into the Persian Gulf (hereafter, the Gulf). Figure 1 shows the location of Qatar in the Middle East. Qatar is a relatively flat peninsula with natural topography that varies from 5 to $103 \mathrm{~m}$ above sea level. It has a hot desert environment and small annual precipitation. Qatar is often hit by Shamals, which are predominantly northwesterly dust storms that occur during the summer.

To analyze changes in climate extremes, it is essential to have continuous time series data with at least daily resolution 

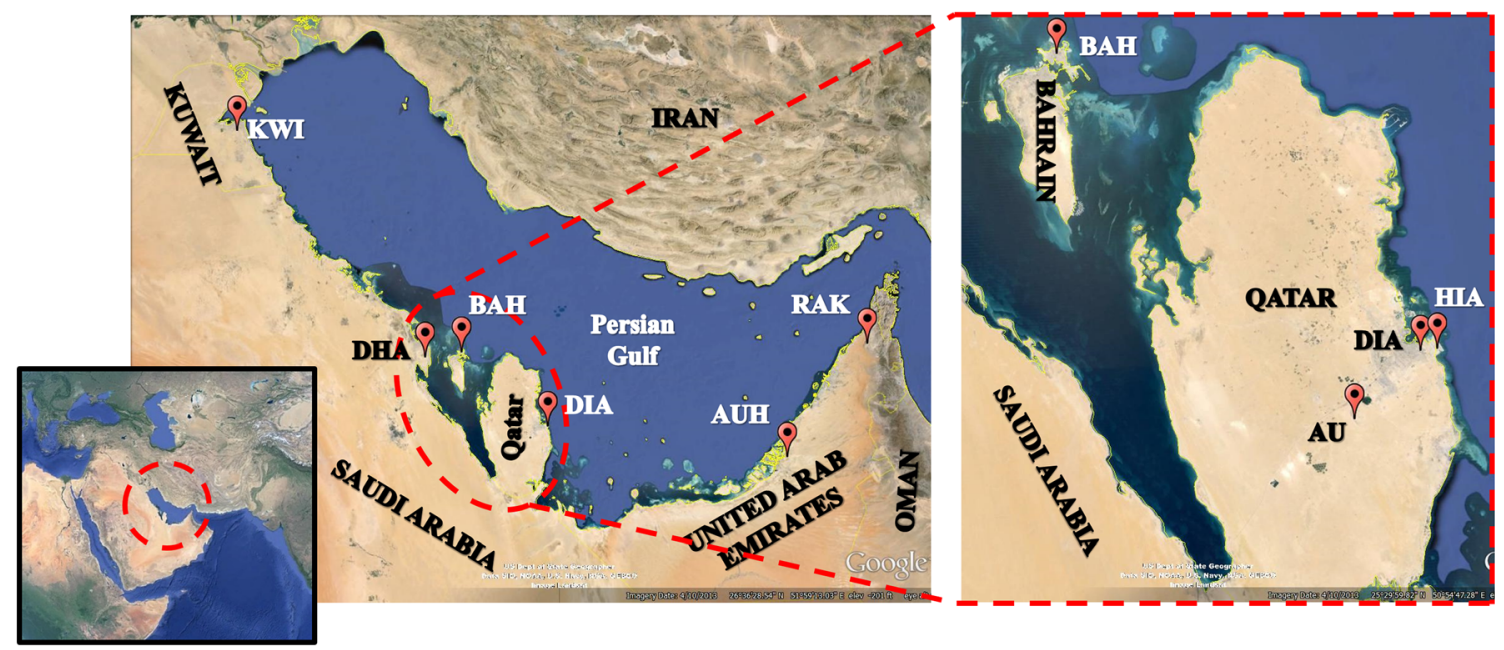

Fig. 1 Map of Qatar with the location of the Qatari stations highlighted: $D I A$ Doha International Airport, $A U$ Al Udeid and HIA Hamad International Airport. Additional stations (AUH Abu Dhabi, $B A H$

(Klein Tank et al. 2009), which allows the detection of the sub-monthly nature of many such extremes. Weather data, including temperature, humidity, wind speed, and wind direction, were obtained from three different measurement stations in Qatar. Metrological data were recorded at the following station locations: Doha International Airport (DIA) and Al Udeid (AU). DIA is located less than $3 \mathrm{~km}$ from the coast and AU is situated $29 \mathrm{~km}$ inland from Qatar's east coast. A separate weather station was also established by the MicroScale Thermal Fluid Lab on a pier $500 \mathrm{~m}$ out to sea from the Hamad International Airport (HIA). These stations recorded a set of high-resolution data to characterize the weather conditions as part of a more comprehensive metrological effort (Singha and Sadr 2012). For comparison purposes, Table 1 lists the details of the three Qatari stations and four other stations in the Gulf region (their locations are shown in Fig. 1). Station data from DIA were selected for the
Bahrain, DHA Dhahran, KWI Kuwait, and RAK Ras al Khaimah) in the region are also highlighted. Courtesy of Google Earth map service

subsequent analysis of the temperature extremes based on the long-term series, daily resolution, and data completeness. Additional datasets were obtained from the same agency for various locations across the region, i.e., Abu Dhabi, Bahrain, Dhahran, Kuwait and Ras Al-Khaimah, for comparison purposes. Data from the other two Qatari sites were used to check the spatial variability of the temperature in Qatar and to evaluate the data quality and homogeneity at DIA.

\section{Methodology}

\subsection{Data quality and homogeneity}

All stations used in this work, shown in Table 1, are located in airport zones and are isolated from the direct effects of rapid urbanization and the construction boom. In particular, this is
Table 1 Location of the weather stations and data details

\begin{tabular}{|c|c|c|c|c|c|}
\hline Station & Location & $\begin{array}{l}\text { Elevation } \\
\text { (above sea level) }\end{array}$ & Analyzed data years & Duration & $\begin{array}{l}\text { Minimum } \\
\text { resolution }\end{array}$ \\
\hline \multirow[t]{3}{*}{ DIA } & \multirow[t]{3}{*}{$+25.26^{\circ} \mathrm{N}+51.57^{\circ} \mathrm{E}$} & \multirow[t]{3}{*}{$11 \mathrm{~m}$} & 1983 to 1995 & \multirow[t]{3}{*}{30 years } & $3 \mathrm{~h}$ \\
\hline & & & 1996 to 2010 & & $1 \mathrm{~h}$ \\
\hline & & & 2010 to 2012 & & $0.5 \mathrm{~h}$ \\
\hline $\mathrm{AU}$ & $+25.12^{\circ} \mathrm{N}+51.32^{\circ} \mathrm{E}$ & $40 \mathrm{~m}$ & $2005,2006,2010$ to 2012 & 5 years & $1 \mathrm{~h}$ \\
\hline HIA & $+25.25^{\circ} \mathrm{N}+51.63^{\circ} \mathrm{E}$ & $10 \mathrm{~m}$ & Jan 2011 to Jun 2012 & 18 months & $0.5 \mathrm{~h}$ \\
\hline AUH & $+24.43^{\circ} \mathrm{N}+54.65^{\circ} \mathrm{E}$ & $27 \mathrm{~m}$ & 1983 to 2015 & 33 years & $1 \mathrm{~h}$ \\
\hline RAK & $+25.61^{\circ} \mathrm{N}+55.93^{\circ} \mathrm{E}$ & $31 \mathrm{~m}$ & 1983 to 2015 & 33 years & $1 \mathrm{~h}$ \\
\hline BAH & $+26.27^{\circ} \mathrm{N}+50.63^{\circ} \mathrm{E}$ & $2 \mathrm{~m}$ & 1983 to 2015 & 33 years & $1 \mathrm{~h}$ \\
\hline DHA & $+26.15^{\circ} \mathrm{N}+50.09^{\circ} \mathrm{E}$ & $26 \mathrm{~m}$ & 1983 to 2012 & 30 years & $1 \mathrm{~h}$ \\
\hline KWI & $+29.22^{\circ} \mathrm{N}+47.96^{\circ} \mathrm{E}$ & $63 \mathrm{~m}$ & 1983 to 2015 & 33 years & $1 \mathrm{~h}$ \\
\hline
\end{tabular}

AU Al Udeid; DIA Doha International Airport; HIA Hamad International Airport; AUH Abu Dhabi International Airport; $B A H$ : Bahrain International Airport; $D H A$ : Dhahran International Airport; KWI: Kuwait International Airport; RAK: Ras Al Khaimah International Airport 
true for the two weather stations in Qatar, which has witnessed rapid economic growth in recent decades. For data quality control and homogeneity checks, the procedures described in the WMO guidance on developing long-term, highquality climate data were followed (Brunet et al. 2008; Klein Tank et al. 2009).

Graphical and statistical techniques were used to inspect the data for various erroneous values. Rigorous quality control ensured that dubious data values or outliers did not affect the subsequent homogeneity results. Outliers are defined as values that fall outside four standard deviations $(\sigma)$ of the daily mean $(\mu)$ value (i.e., $\mu \pm 4 \sigma$ ). These values in the daily minimum and maximum temperature series were first identified and carefully checked individually before their removal from the dataset. Errors caused by incorrect keying of data values and nonexistent dates (e.g., 31 November) were withdrawn from the data series. Additionally, days that had only a single observation without any meta-data support were removed. Finally, interpolation was used to obtain the hourly data from 1983 to 1995 , where the weather data were recorded once every $3 \mathrm{~h}$. A verification mechanism was implemented to flag any significant deviations between consecutive data points, which were subsequently investigated by manual inspection. Figure 2 shows the interpolated dataset from the original hourly data for two randomly selected months, using linear interpolation for temperatures between the 3-hourly time intervals used in the original data from 1983 to 1995 . The interpolated dataset almost reproduces the original hourly temperature data with only minor discrepancies. The small differences between the original dataset and interpolated dataset show that linear interpolation can be used to expand the 3-hourly data from 1983 to 1995 into hourly data.

After quality control, the next step was to check the temporal homogeneity of the long-term data. Inhomogeneity can be caused by a variety of factors, e.g., station relocation, changing surroundings, and instrument changes. The primary objective of data homogenization is to ensure that variations in the recorded values are only due to climatic processes. The RHtestV3 software package (available for the scientific community from http://etccdi.pacificclimate.org/software.shtml) was used to assess the data homogeneity (Wang and Feng 2010). The software can detect multiple shifts in data based on the penalized maximal $t$ and $F$ tests (Wang 2008; Wang et al. 2008) depending on the availability of a reference station. Monthly maximum and minimum temperature series were first tested for homogeneity using the penalized maximal $t$ test (Wang et al. 2008; Wang 2008). It showed a zero trend in the data series for the entire recorded period. The daily data series were then tested with the RHtestV3 software and compared with the outcome of the monthly data series. This test is applied when a reference station is available, as in this case. A homogeneous reference station from Bahrain (Donat et al. 2013; AlSarmi and Washington 2011) was selected as the reference station to check the homogeneity of the data series from DIA.

A significant step change seen in the maximum temperature series was determined to be a result of climatic factors in January 1998, which coincided with the heating associated with the 1997/1998 El Niño year. Several stations within the region also reported this unexpected heating (AlSarmi and Washington 2011; Donat et al. 2013). There were also reports (e.g., Webster et al. 1999; Yu et al. 1999) of anomalous rises of the sea surface temperature in the Indian Ocean, which could have been related to the El Niño effect. The original data during this period that were used as the inhomogeneities in the maximum temperature series might be related to El Niño heating. No significant inhomogeneities were detected in the minimum temperature series.

The annual variation of relative humidity was compiled in a similar manner to show the long-term trend of annual variation. The heat index is a single parameter that combines temperature and relative humidity, which is calculated from hourly
Fig. 2 Comparison of the original hourly temperature data with interpolated data using data at time points at 12 a.m., 3 a.m., 6 a.m., 9 a.m., 12 p.m., 3 p.m., 6 p.m., and 9 p.m.

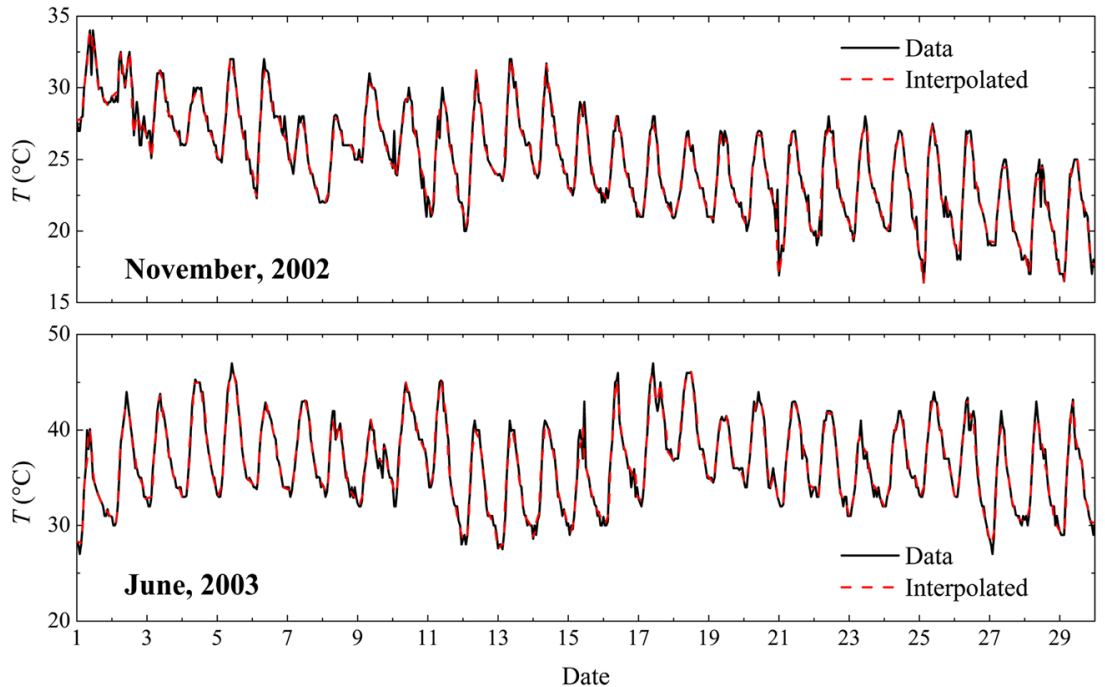


temperature and humidity data. The thermohygrometric index $(H I)$, commonly and hereafter referred as the heat index, measures the perceived comfort level of human beings in terms of temperature and relative humidity (Unger 1999). The value of the heat index can be obtained from the relation according to the US National Weather Service, described by Eq. (1):

$$
\mathrm{HI}=\mathrm{T}-(0.55-0.0055 \mathrm{RH})(\mathrm{T}-14.5)
$$

where $T$ is the air temperature $\left({ }^{\circ} \mathrm{C}\right)$ and $R$ is relative humidity (\%). The index is commonly used to characterize the existence of a heat wave, which is considered a prolonged period of unwarranted hot and humid conditions that persists for at least three consecutive days (Deo et al. 2007). The heat index time series was converted to an indicator for heat waves (i.e., the Heat Wave Index) using the approach devised by Meehl and Tebaldi (2004). A 3-day moving average of the heat index was computed and the maximum of the 3-day running mean taken to represent the worst annual heat wave event of the given year. The procedure was repeated for each year, which yielded a time series of the Heat Wave Index in Doha.

\subsection{Analysis method}

Overall, 27 climate indices were defined to describe the intensity, frequency, and duration of extreme events by the ETCCDI. These indices are statistically robust, and they can easily be used for comparisons of different regions. There were 16 temperature and 11 precipitation indices determined from the daily maximum and minimum temperature and daily precipitation series; their detailed definitions can be found in Zhang et al. (2011). The indices were categorized into five groups (Alexander et al. 2006): (1) absolute; (2) percentilebased; (3) threshold; (4) duration; and (5) miscellaneous. Table 2 summarizes the 12 indices chosen in this study that are relevant to the climate of the target region. The selected indices were calculated from both annual and seasonal data. Two seasons were assumed: dry season (May-October) and wet season (January-April, November, and December). These indices were calculated using the RClimDex software developed at the Climate Research Division, Environment Canada. The base period for the calculation of the percentile-based indices was chosen to be 1984-2011, because data were available beginning from 1983. For the base period, less than $1 \%$ of the daily data points were missing. For the index calculations, annual indices were not determined for a given year if (a) more than 15 days were missing in that year or (b) if 3 or more days were missing in any given month during the year.

The temperature data were analyzed using the nonparametric methods of the Mann-Kendall test to establish the trend in the time series and the Thiel-Sen estimator to determine the true slope (Sen 1968). One of the advantages of the MannKendall test is that there is no presumption regarding the underlying probability distribution of the sample data being analyzed. The annual (and seasonal) indices were examined using the Mann-Kendall test to determine whether monotonic increasing or decreasing trends existed. The slopes were then estimated using the Thiel-Sen estimator, which is a simple nonparametric estimation of the true slope, if a slope is present in the dataset. The nonparametric approach has been widely applied in statistical meteorological studies (Zhang et al. 2005; Aguilar et al. 2009; Butt et al. 2009; AlSarmi and Washington 2014).

\section{Weather pattern of Qatar}

\subsection{Spatial variation}

The high-resolution dataset listed in Table 1 is a continuous complete 18-month dataset that was compared against the National Climatic Data Center datasets at DIA and AU.

Table 2 Summary of temperature indices

\begin{tabular}{|c|c|c|c|c|}
\hline Category & Index & Index name & Definition & Unit \\
\hline \multirow[t]{4}{*}{ Absolute indices } & TXx & $\operatorname{Max} T_{\max }$ & Annual max. of daily max. Temperature (TX) & ${ }^{\circ} \mathrm{C}$ \\
\hline & TXn & Min $T_{\max }$ & Annual min. of daily max. Temperature (TX) & ${ }^{\circ} \mathrm{C}$ \\
\hline & $\mathrm{TNx}$ & $\operatorname{Max} \mathrm{T}_{\min }$ & Annual max. of daily min. Temperature (TN) & ${ }^{\circ} \mathrm{C}$ \\
\hline & $\mathrm{TNn}$ & $\operatorname{Min} T_{\min }$ & Annual min. of daily min. Temperature (TN) & ${ }^{\circ} \mathrm{C}$ \\
\hline \multirow[t]{4}{*}{ Percentile-based } & TX10p & Cool days & Annual number of days when $\mathrm{TX}<10$ th percentile & days \\
\hline & TX90p & Warm days & Annual number of days when TX $>$ 90th percentile & days \\
\hline & TN10p & Cool nights & Annual number of days when $\mathrm{TN}<10$ th percentile & days \\
\hline & TN90p & Warm nights & Annual number of days when $\mathrm{TN}>90$ th percentile & days \\
\hline \multirow[t]{2}{*}{ Threshold indices } & SU25 & Summer days & Annual count of days when $\mathrm{TX}>25^{\circ} \mathrm{C}$ & days \\
\hline & TR20 & Tropical nights & Annual count of nights when $\mathrm{TN}>20^{\circ} \mathrm{C}$ & days \\
\hline \multirow[t]{2}{*}{ Miscellaneous indices } & DTR & Diurnal temperature range & Monthly mean difference between TX and TN & ${ }^{\circ} \mathrm{C}$ \\
\hline & ETR & Extreme temperature range & Difference between maximum TX and minimum TN in the year & ${ }^{\circ} \mathrm{C}$ \\
\hline
\end{tabular}


Figure 3 shows a scatter plot of the average daily temperatures for all three stations. The average daily temperatures at HIA and AU are $0.34{ }^{\circ} \mathrm{C}$ warmer and $0.85^{\circ} \mathrm{C}$ cooler, respectively, than at DIA. The correlations were performed over the period from January 2011 to June 2012. In each case, the station with the long-term data, i.e., DIA, was chosen as the base station. The solid line indicates a perfect correlation, and the $y$-intercepts are 0.1 and $-2.3{ }^{\circ} \mathrm{C}$ for DIA and AU, respectively. The slopes of the best-fitted lines in Fig. 3 are 0.999 and 1.068 for HIA and AU, respectively. AU exhibits lower daily temperatures compared with DIA for the region below $20^{\circ} \mathrm{C}$. This result can be attributed to the fact that $\mathrm{AU}$ is located $29 \mathrm{~km}$ inland from the sea and hence, it experiences a greater temperature drop after sunset compared with the coastal stations, where the sea regulates the temperature somewhat. Overall, there is no significant difference in the daily temperature data for the three weather stations, inland (AU), coastal (DIA), and offshore (HIA), which supports the analysis of data quality and homogeneity discussed in Section 3.1. Thus, based on the data available, it was assumed that the long-term temperature record available at DIA was a good representation of the temperature of the State of Qatar and this particular section of the Gulf. The subsequent analysis will include the 30-year daily temperature series from DIA.

\subsection{Annual variation}

The temperature dataset was first analyzed for annual variation to ensure there were no significant interannual changes. Figure 4a shows the 30-year average hourly variation of temperature for an entire year (365 days). The minimum temperature recorded was $5{ }^{\circ} \mathrm{C}$ and the maximum temperature was $50^{\circ} \mathrm{C}$ (between 1983 and 2012, inclusive). It can be seen from the figure that, on average, the daily temperatures vary between 13 and $42{ }^{\circ} \mathrm{C}$. The 30-year mean annual minimum and maximum temperatures are 24 and $32{ }^{\circ} \mathrm{C}$, respectively. Figure $4 \mathrm{~b}$ shows the standard deviation of the 30 -year hourly average temperature observations illustrated in Fig. 4a. This figure shows that for the 30-year duration of the data examined here, the annual temperature variations are often highest during the afternoon hours. Moreover,
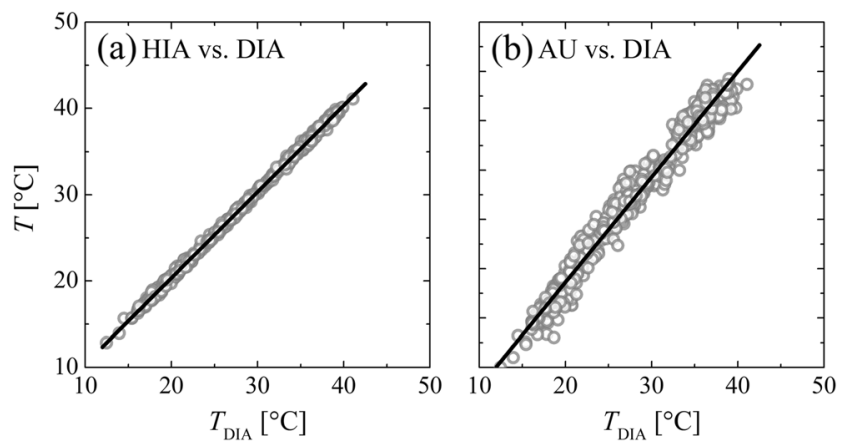

Fig. 3 Scatter plots of averaged daily temperatures between a DIA-HIA and $\mathbf{b}$ DIA-AU; solid red line represents the ideal correlation, a line with a $45^{\circ}$ slope

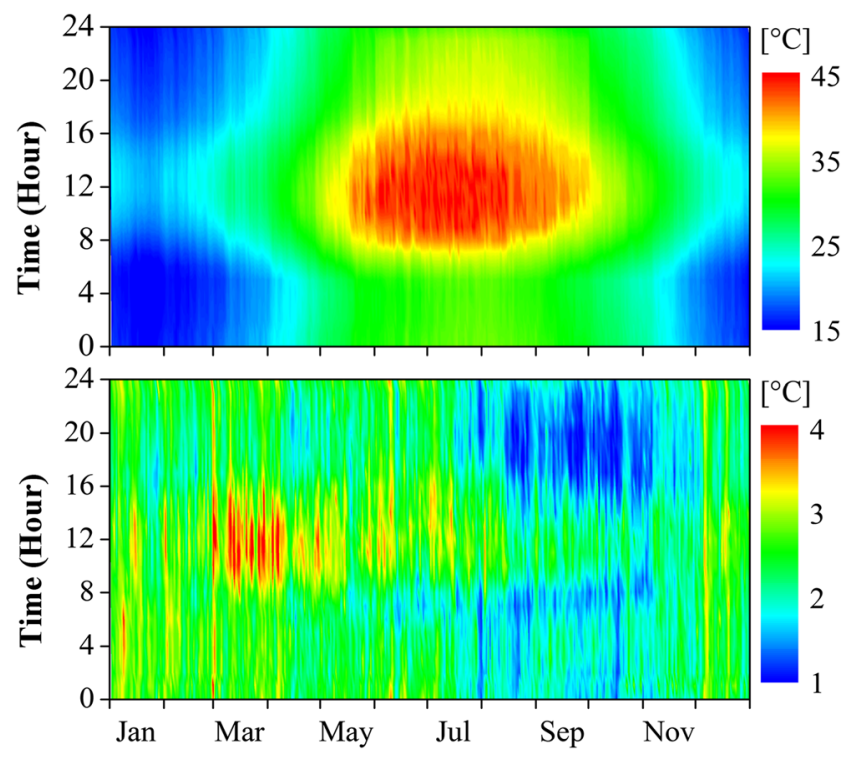

Fig. 4 Averaged 30-year hourly temperature variation: a top figure: average temperature distribution, and b bottom figure: standard deviation of the average plot

temperature variations are lowest during the months of August through November at any given time.

Figure $5 \mathrm{a}$ shows the 30 -year mean hourly variation of relative humidity from 1983 to 2012 in Doha, Qatar. The average daily relative humidity fluctuates between 17 and $85 \%$, where the mean annual minimum and maximum relative humidity values are 37 and $70 \%$, respectively. Figure 5 b shows the standard deviation of the 30 -year hourly average humidity observations of Fig. 5a. The annual fluctuations in humidity are highest in the dry season months during the night hours. For most of the winter months (December-February), the

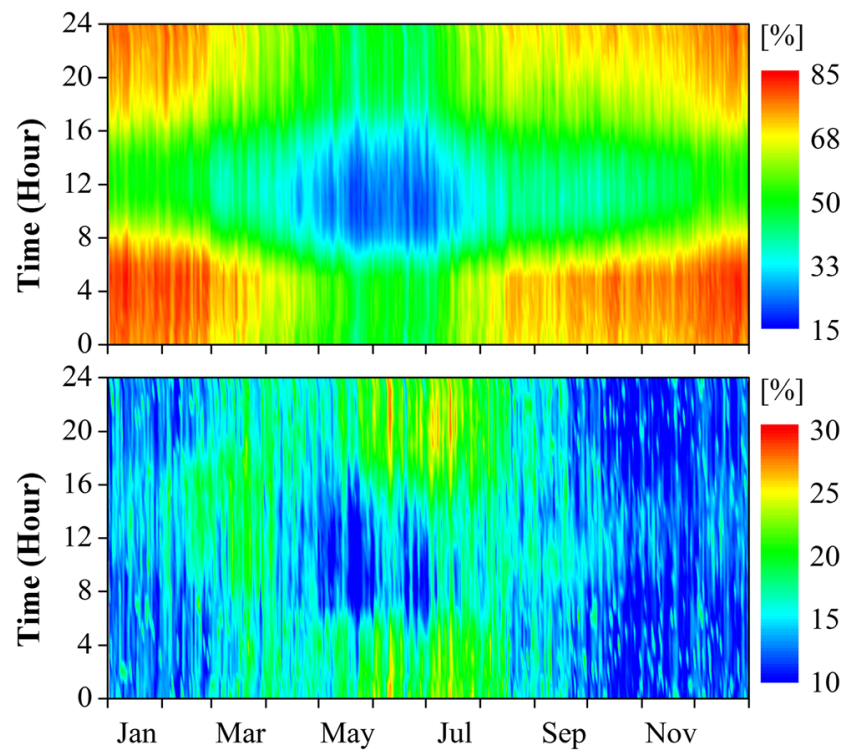

Fig. 5 Averaged 30-year hourly relative humidity variation: a top figure: average relative humidity distribution, and $\mathbf{b}$ bottom figure: standard deviation of the average plot 
fluctuations in relative humidity are relatively small. In general, summer months can be characterized by hot, dry weather, whereas winter months exhibit milder temperatures and higher humidity compared with summer. Figure 6 a shows the 30 -year average heat index variation. The heat index reaches dangerous levels, defined as a heat index value $>41^{\circ} \mathrm{C}$, mostly between July and September when the humidity increases. The annual fluctuation of the heat index is shown in Fig. 6b; the variations are highest during the night from July to September and in January.

\section{Trends in extreme temperature events}

\subsection{Long-term variation of percentile-based indices}

Both Figs. 7 and 8 show a negative trend for the frequency of cool days (TX10p) and cool nights (TN10p) and a positive trend for warm days (TX90p) and warm nights (TN10p), respectively, in Qatar from 1983 to 2012. These are the percentile indices, which represent the positive and negative tails of the temperature distributions of the daytime and nighttime during this period. These figures show a positive trend for the number of warm days and nights and a negative trend for the number of cool days and nights. An increase in the frequency of these indices indicates a shift in the temperature distributions toward higher temperatures. Figures 7 and 8 show that the number of cool days and nights decreases along with a simultaneous increase in the number of warm days and nights. These figures show that the temperature distribution in Doha has undergone an asymmetric shift toward higher temperatures from 1983 to 2012 . The rise of

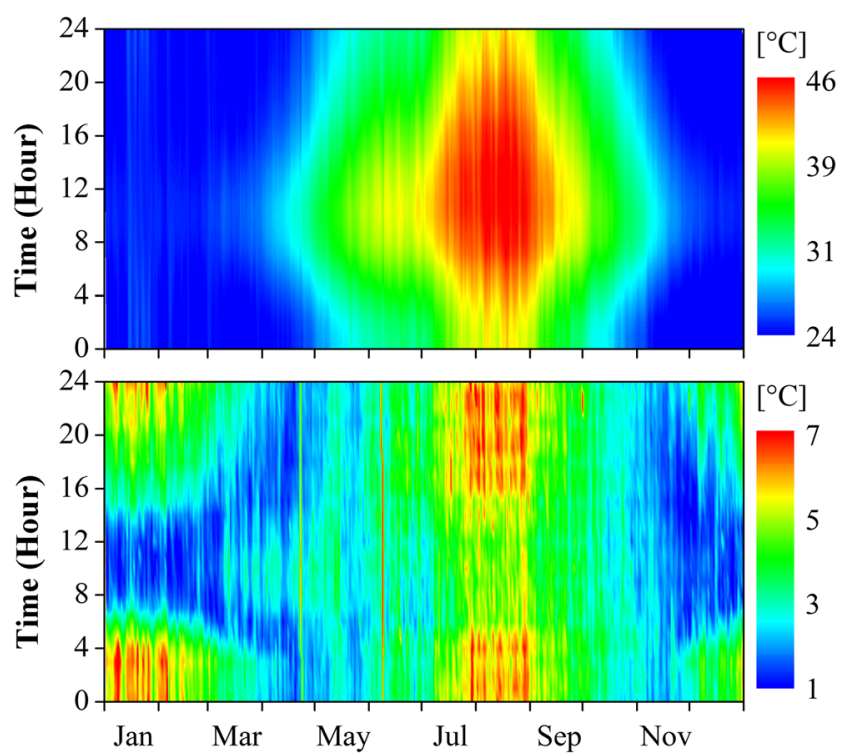

Fig. 6 Averaged 30-year hourly variation of the heat index (HI): a top figure: average $\mathrm{HI}$ distribution, and $\mathbf{b}$ bottom figure: standard deviation of the average plot
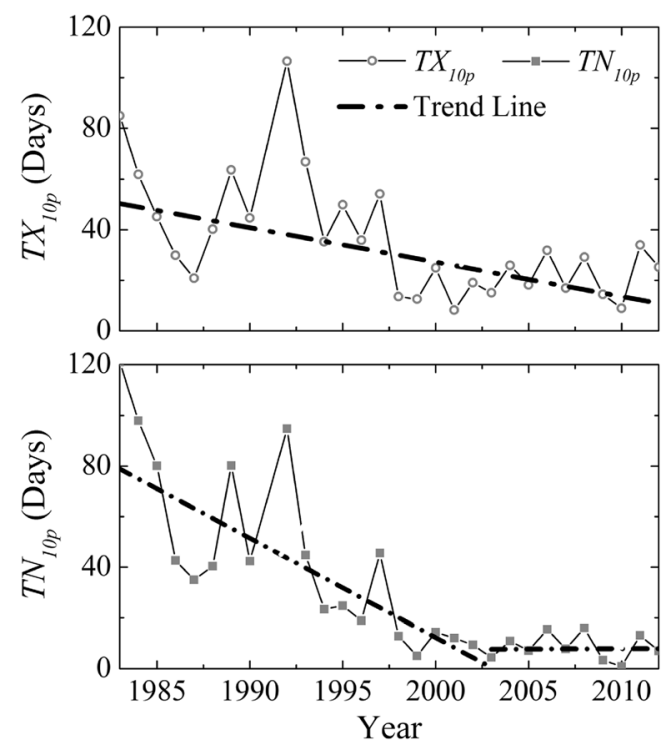

Fig. 7 Annual frequency of cool days (top) and cool nights (bottom)

the minimum temperature occurred at a higher rate than the increase of the maximum temperature. Karl et al. (1993) observed similar trends in North America, the former Soviet Union, China, Japan, South Africa, and Sudan from 1951 to 1990, where the authors noticed substantial warming of the minimum temperature relative to the maximum. Our analysis also showed that there was a substantial decline in the number of cool nights before 2000, while the number of warm nights increased rapidly since 2000 .

Table 3 shows the seasonal trend for the percentile indices during the dry season (May-October) and wet season (January-April, November, and December). The nighttime trend slopes (both annual and seasonal) are almost twice as large as the corresponding daytime trend slopes. Moreover, the dry season trend slopes are generally higher than the wet season

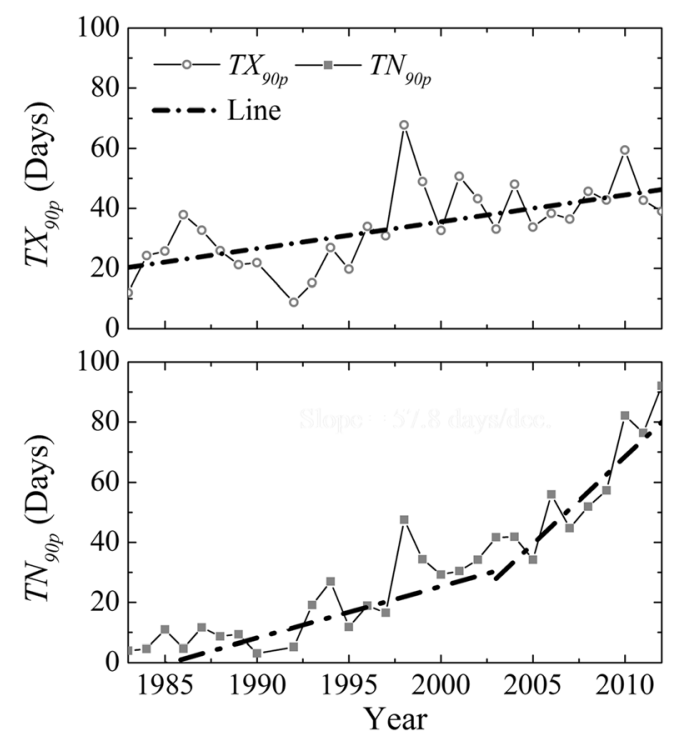

Fig. 8 Annual frequency of warm days (top) and warm nights (bottom) 
Table 3 Slope of best fitting curve for percentile indices; significant changes (at $95 \%$ confidence level) are indicated in bold

\begin{tabular}{lccc}
\hline & \multicolumn{2}{l}{ Trend [days/decade] } \\
\cline { 2 - 4 } & Dry season & Wet season & Annual \\
\hline TX10p (cool days) & $-\mathbf{7}$ & -4.9 & $\mathbf{- 1 3 . 6}$ \\
TX90p (warm days) & $\mathbf{5 . 6}$ & $\mathbf{3 . 9}$ & $\mathbf{9}$ \\
TN10p (cool nights) & $\mathbf{- 1 7 . 2}$ & $\mathbf{- 9 . 4}$ & $\mathbf{- 3 9 . 2}^{(1983-2003)}$ \\
& & & $-0.03^{(2003-2012)}$ \\
TN90p (warm nights) & $\mathbf{9 . 1}$ & $\mathbf{9 . 5}$ & $\mathbf{1 7 . 2}^{(1983-2003)}$ \\
& & & $\mathbf{5 7 . 8}$ \\
TNn & $\mathbf{1 . 8 5}$ & $\mathbf{1}$ & $\mathbf{1}$ \\
TNx & $\mathbf{0 . 9 3}$ & $\mathbf{0 . 6 6}$ & $\mathbf{0 . 9 3}$ \\
TXn & $\mathbf{0 . 7 5}$ & 0 & 0 \\
TXx & $\mathbf{0 . 4 5}$ & 0.5 & 0.45 \\
DTR & $-\mathbf{0 . 5 2}$ & $-\mathbf{0 . 4 4}$ & $-\mathbf{0 . 4 8}$ \\
ETR & $-\mathbf{1 . 4 3}$ & -0.44 & -0.37 \\
\hline
\end{tabular}

$\S$ Trend value calculated for the period from 1983 to 2005 because the number of days recorded for TN10p from 2005 onwards was zero in the dry season

indices. These results show that dry season heating is more prominent during the year in Doha. Compared with the data obtained by Almazroui et al. (2014) for Dhahran in Saudi Arabia, the trend for cool/warm nights is more pronounced than in Saudi Arabia. In contrast, the number of cool/warm days is at least $30 \%$ lower than in the corresponding counterparts of Saudi Arabia. There is a smaller difference in the trends of warm days/nights in Qatar than in Saudi Arabia.

Warming is evident because the nighttime rate of change is almost double that of the day indices. Similar trends have been observed in many parts of the world (Donat and Alexander 2012), including the Arabian region (Donat et al. 2013). The warming trends in the percentile-based indices for Qatar are greater than the corresponding averages for the Arabian Peninsula, as mentioned before. In Fig. 7, the increases in the number of warm days/nights occurred gradually during the 1980 s, except for a sharp rise in the 1990s for both indices. Region-wide averaged results reported by Zhang et al. (2005) and Donat et al. (2013) have shown similar trends to the single-station results illustrated in Figs. 7 and 8. Because the trends calculated by Zhang et al. (2005) are for 1970-2003 rather than 19832012 as in this study, the data show that accelerated warming across the Gulf area has occurred since 2000. Additionally, the spike in the percentage of warm days and nights observed in 1998 can be attributed to the exceptional heating caused by the 1998 El Niño year, as mentioned above.

\subsection{Long-term variation of absolute indices}

Figure 9 shows the rate of change in the number of summer days and tropical nights in Qatar from 1983 to 2012. This

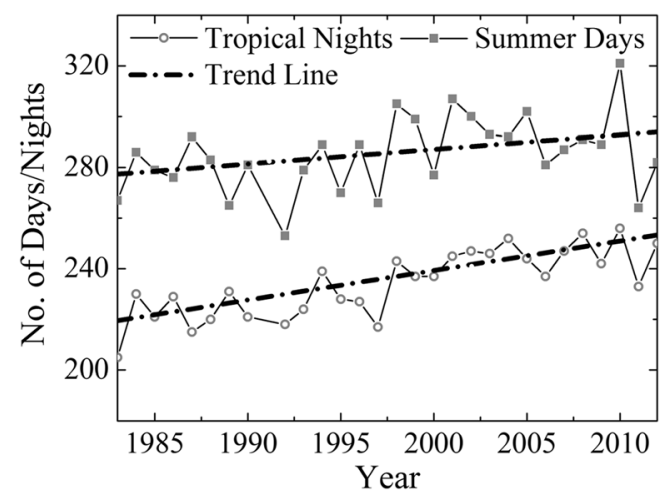

Fig. 9 Interannual occurrence of summer days and tropical nights

figure shows a significant increase in both these indices with the rise in the number the tropical nights being almost double that of summer days. The number of tropical nights has increased by approximately 30 days between 1983 and 2012. Similar results have been reported by Alexander et al. (2006) for several larger regions in the world. Figure 10 shows the interannual variation of the average minimum temperature together with its annual minimum (TNn) and maximum (TNx). The annual average daily minimum temperature, $\mathrm{TNx}$, and TNn have all increased at approximately the same rate of about $1{ }^{\circ} \mathrm{C} /$ decade. During the 30 -year period, the increase in TNn exhibits a slightly higher rate with greater fluctuations compared with TNx. Figure 11 shows the trends of the daily maximum temperature, which reflects a moderate increase of approximately $0.5^{\circ} \mathrm{C} /$ decade. TXx occurs in the dry season, whereas TNn occurs in the wet season. This figure shows that the trends for the average daily maximum and TXx are smaller in magnitude when compared with $\mathrm{TNn}$ and $\mathrm{TNx}$. No long-term variation is evident in the TXn series.

Table 3 shows the slopes for both the annual and the seasonal temperature extremes. The dry season indices, which are statistically significant, have larger slope values than their winter counterparts. The values for the indices associated with the daily minimum temperature are greater than for their counterparts for the daily maximum temperature, regardless of the

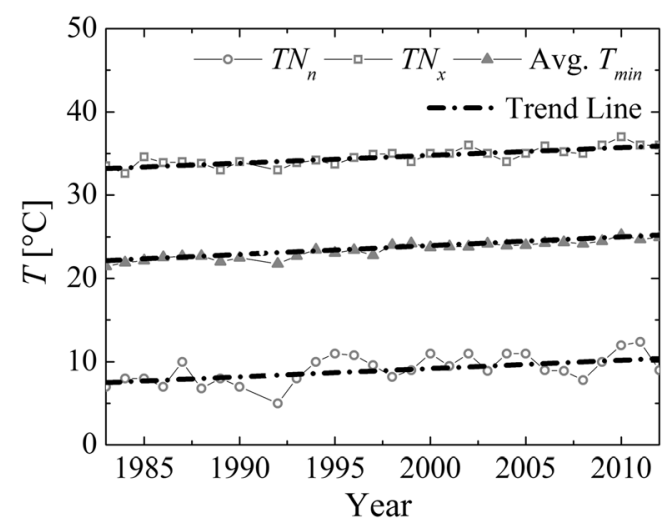

Fig. 10 Changes in the annual TNx, average minimum temperature, and $\mathrm{TNn}$ 


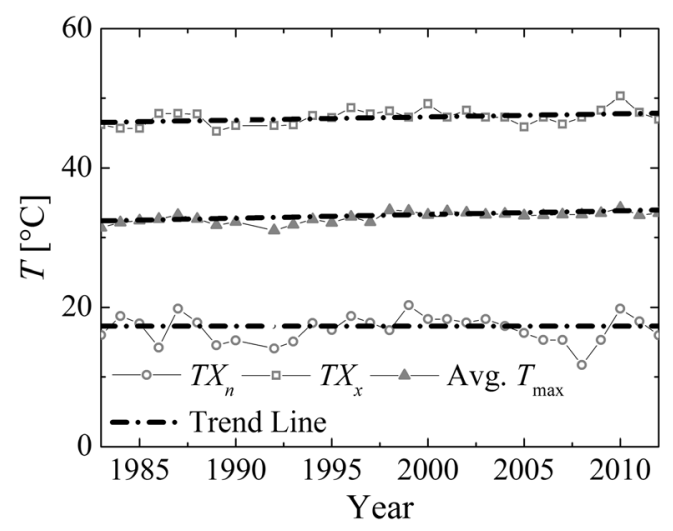

Fig. 11 Changes in annual maximum of the daily maximum TXx and average maximum and minimum values of daily maximum temperature TXn

season. This indicates a more significant warming trend during dry season, particularly during the nighttime. Similar to the comparison of the percentile-based indices, the minimum temperatures in Doha increased at a faster rate than their corresponding values in Dhahran, Saudi Arabia (Almazroui et al. 2014). These results are consistent with the average trends in the Middle East (AlSarmi and Washington 2014; Almazroui et al. 2014). Both studies observed a significant increase in the maximum value of the daily maximum/minimum temperatures. This more rapid warming of the daily minimum temperature, in comparison with the daily maximum temperature, results in a negative trend for the monthly mean difference between TX and TN, daily temperature range (DTR), and extreme temperature range (ETR). Figure 12 shows that both the DTR and ETR parameters exhibit a decreasing trend, which has a slope that is approximately $0.5^{\circ} \mathrm{C} / \mathrm{decade}$.

\subsection{Comparing the climatic trends in Qatar and the Gulf Region}

Table 4 provides a comparison of the annual trends of the presented indices for Qatar compared with several other countries that border the Gulf, using weather data obtained from

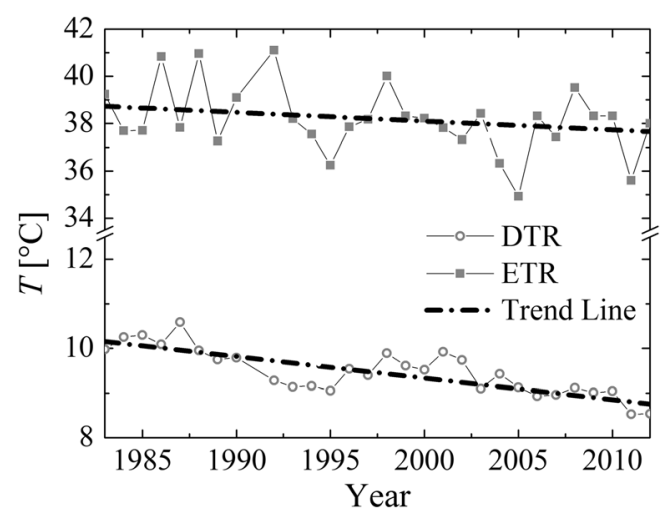

Fig. 12 Interannual variation of the diurnal temperature range (DTR) and the extreme temperature range (ETR) the US National Centers for Environmental Information. Abu Dhabi and Ras Al-Khaimah are located east of Qatar, and both cities exhibit similar warming trends to that reported for Doha. The trends are of comparable intensities, which indicate a general warming pattern for the southeastern coasts of the Gulf. Temperature indices were also calculated for Kuwait, which is located further toward the northwestern part of this region. Kuwait has experienced similar warming trends regarding the frequency of warm nights/days and cool nights/ days; however, the intensities are less than at Doha. Detailed numerical results for the northern part of the Gulf are unavailable; however, Marofi et al. (2011) showed that Bushehr, Iran, which is located approximately $400 \mathrm{~km}$ northwest of Doha, has experienced significant warming in recent decades. Warming can be mainly observed by the higher frequency of warm nights and days, reduction in the number of cool nights and days, and a more significant rise in the minimum temperature indices. Another Iranian location, Kish Island, which is located approximately $300 \mathrm{~km}$ northeast of Doha, has also witnessed warming but less severe compared with Doha and Bushehr (Marofi et al. 2011). The minimum temperatures have increased, and the occurrence of summer days and tropical nights has increased. In summary, the trends shown in this study are consistent with the pattern between 1981 and 2010 in Dhahran, Saudi Arabia, which also showed an increase in the number of cool/warm nights, although with a slower rate of increase than in Qatar (Almazroui et al. 2014). The seasonal temperature trends for Qatar are also similar to Saudi Arabia. There has been a sharp increase in the number of warm days and nights during the warm seasons in Saudi Arabia from 1981 to 2010 and a significant decrease in the number of cool nights during the cool season (Islam et al. 2014).

\subsection{Effects of humidity and long-term trend of heat index}

The annual variations in the maximum, minimum, and mean relative humidity for Doha were also computed, and they are plotted in Fig. 13. The relative humidity depends on both the specific humidity and temperature. The results in Fig. 13 show that the humidity indices in Qatar have been decreasing at a rate of approximately $1.5 \% /$ decade. The associated $p$ values for the best-fitting slopes are all $<0.005$, which indicates that the slopes are statistically significant at the $95 \%$ confidence level. The annual reduction in the relative humidity supports the earlier warming trends found in the extreme temperature indices. A decrease in relative humidity can be due to the following: a decrease in specific humidity (i.e., a decrease in the mass of water vapor in a unit mass of moist air), or an increase in saturated vapor pressure caused by an increase in temperature.

The long-term trends of the annual maximum and minimum values of the heat index, shown in Table 5, reflect the intensified heating during the dry season. Figure 14 shows a 
Table 4 Comparison of the annual trends between different cities discussed in the text; significant changes (at $95 \%$ confidence level) are indicated in bold

\begin{tabular}{|c|c|c|c|c|c|c|c|}
\hline & & \multicolumn{6}{|c|}{ 1983-2012 } \\
\hline TX10p & {$[\% / \mathrm{dec}]$} & -4.32 & -4.17 & -4.56 & -4.53 & -2.95 & -4.23 \\
\hline TN10p & {$[\% / \mathrm{dec}]$} & -8.03 & -3.57 & -6.12 & -5.19 & -3.51 & -4.65 \\
\hline TX90p & {$[\% / \mathrm{dec}]$} & 2.6 & 3.21 & 2.47 & 3.00 & 2.35 & 5.18 \\
\hline TN90p & {$[\% / \mathrm{dec}]$} & 6.92 & 5.12 & 5.79 & 3.05 & 3.17 & 2.58 \\
\hline SU25 & [days/dec] & 6.31 & 3.68 & 7.46 & 8.06 & 3.94 & 6.61 \\
\hline TR20 & {$[$ nights $/$ dec $]$} & 11.86 & 4.55 & 14.48 & 11.81 & 5.07 & 5.64 \\
\hline $\mathrm{TNx}$ & {$\left[{ }^{\circ} \mathrm{C} / \mathrm{dec}\right]$} & 0.97 & 0.53 & 1.00 & 0.29 & 0.55 & 0.26 \\
\hline $\mathrm{TNn}$ & {$\left[{ }^{\circ} \mathrm{C} / \mathrm{dec}\right]$} & 1.14 & 0.71 & 0.81 & 0.62 & 0.24 & -0.22 \\
\hline TXx & {$\left[{ }^{\circ} \mathrm{C} / \mathrm{dec}\right]$} & 0.55 & 1.02 & 0.34 & 0.56 & 0.37 & 0.79 \\
\hline TXn & {$\left[{ }^{\circ} \mathrm{C} / \mathrm{dec}\right]$} & -0.09 & 0.08 & 0.48 & 0.68 & 0.09 & 0.51 \\
\hline DTR & {$\left[{ }^{\circ} \mathrm{C} / \mathrm{dec}\right]$} & -0.47 & 0.04 & -0.21 & -0.06 & 0.04 & 0.37 \\
\hline
\end{tabular}

statistically significant upward trend of $1.57^{\circ} \mathrm{C} /$ decade of the Heat Wave Index. The 3-day running mean temperature is consistently $>41^{\circ} \mathrm{C}$ through most of the three decades, which could cause serious health risks such as heat stroke. Persistently high temperatures have been shown to increase the mortality rate in the temperate regions of Europe and North America (Kovats and Jendritzky 2006; Martens 1998). There are only limited studies on the impact of climate change on the parameters of importance for Qatari national interests, such as the vulnerability of natural resources such as water, and the health impact of its residents, and the margins of their adaptability are becoming increasingly limited. This is a gap yet to be fulfilled.

Min. $H I_{\min }$ minimum of minimum daily heat index, Max $H I_{\text {min }}$ maximum of minimum daily heat index,

Min. $H I_{\max }$ minimum of maximum daily heat index, Max $H I_{\text {max }}$ maximum of maximum daily heat index

\section{Discussion}

The presented results indicate statistically significant trends in the temperature indices associated with the heating trend in

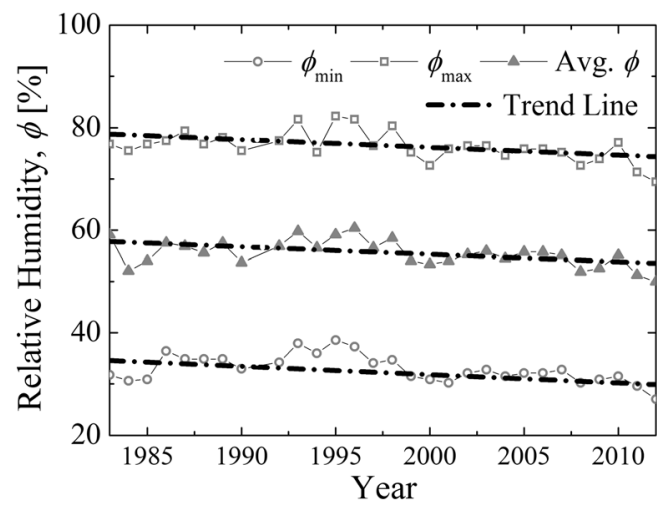

Fig. 13 Interannual trends of maximum, minimum, and average humidity. The $p$ values for the slope of the best fitting curve are 0.004 , 0.005 , and 0.002 for $\phi_{\min }$, average $\phi$, and $\phi_{\max }$, respectively
Qatar. In particular, the results show a significant increase in the minimum temperature, which reflects a reduction in the DTR for Qatar. Several studies have investigated the rise in the minimum temperature in the Arabian Peninsula, which is attributed to the warming trend of changes in atmospheric circulations over the Mediterranean Sea, Indian Ocean, and Sudan (Almazroui et al. 2014; AlSarmi and Washington 2014). The Kendall tau correlation coefficient between the DTR and averaged humidity in Qatar is 0.28 with a $p$ value of 0.035 , which is statistically significant, indicating a strong relation between the relative humidity and DTR. This observation is consistent with the reported regional decrease in the dew point temperature over the southeastern and southern Arabian Peninsula (AlSarmi and Washington 2014).

In addition to the changes in the regional weather pattern, the rapid economic growth in Qatar might also intensify the warming trend. According to the World Bank World Development Indicator Data Bank, Qatar has observed a fivefold increase in population, from approximately 0.3 million in 1983 to over 2 million in 2013 (World Bank Group 2014a). The urban population increased from 90 to over $95 \%$ of the total population during the same period. An overwhelming majority of the population (>85\% in the 2010 census) is concentrated around Doha (the national capital and largest city in the country) and its adjoining suburbs. The overall

Table 5 Slope of the best fitting curve for the extremes of heat indices; significant changes (at $95 \%$ confidence level) are indicated in bold

\begin{tabular}{llll}
\hline & \multicolumn{2}{l}{ Trend $\left[{ }^{\circ} \mathrm{C} /\right.$ decade $]$} \\
\cline { 2 - 4 } & Annual & Dry season & Wet season \\
\hline Min. $H I_{\min }$ & 0.01 & 2.4 & 0.01 \\
Max. $H I_{\min }$ & $\mathbf{1 . 1 7}$ & $\mathbf{1 . 8 8}$ & 0.58 \\
Min. $H I_{\max }$ & 0.44 & $\mathbf{1 . 6 9}$ & $\mathbf{0 . 4 4}$ \\
Max. $H I_{\max }$ & $\mathbf{1 . 7 9}$ & $\mathbf{1 . 7 9}$ & 1.50 \\
\hline
\end{tabular}




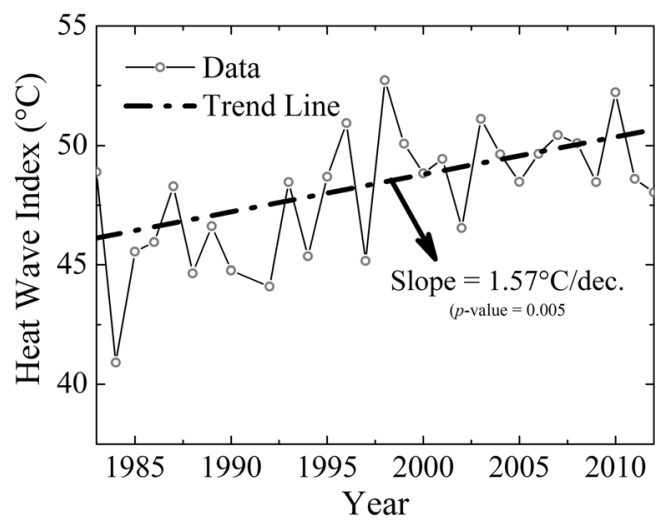

Fig. 14 Interannual trend of the Heat Wave Index. Data obtained from the World Bank Open Data (data.worldbank.org)

population density in Doha is approximately 3000 persons/ $\mathrm{km}^{2}$, with the maximum value within the city of greater than 10,000 persons $/ \mathrm{km}^{2}$. DIA is nowadays located in a highly urbanized area, and urbanization is one of the primary causes of an intensified heat island effect, and an increase in population has been shown to correlate with terrain warming in urban areas (Chung et al. 2004). Published literature has noted that urban warming is more pronounced during summer evenings (Karl et al. 1993) because urban structures release heat that has been absorbed during the day. Moreover, the widespread use of air conditioning, which dissipates warm air outdoors, could be another primary reason for pronounced warming during summer evenings. Similar climatic trends due to urbanization have been reported in Bahrain (Elagib and Abdu 2010). Cyprus (Price et al. 1999), and Riyadh, Saudi Arabia (Qureshi and Khan 1994). Urbanization might explain, at least partially, the rapid increase in the temperature indicators shown in Table 3 during the dry season in Doha.

Finally, the rapid economic expansion in Qatar during recent decades might also have further intensified the rapid warming trend in the country over the past few years. According to the World Bank, the total energy consumption in the country increased from $5000 \mathrm{kt}$ of oil equivalent in 1983 to 33, $000 \mathrm{kt}$ of oil equivalent in 2011, an almost sevenfold increase (World Bank Group 2014b). This increase implies higher energy consumption per capita during the same period. Industrial expansion and development increase the production of greenhouse gases such as carbon dioxide, methane, nitrous oxide, and water vapor. In addition to the rapid growth of the oil-gas processing industry in Qatar, the Qatar Statistic Authority has reported that the number of vehicles registered in Qatar has increased by almost $230 \%$ over the period 20002010. Automobiles are a major contributor to urban pollution and significantly raise the level of greenhouse gases. The amount of greenhouse gas emissions increased sixfold for carbon dioxide, and those for nitrous oxide more than doubled between 1990 and 2011 (World Bank Group 2014c). Figure 15 shows the variation of total carbon dioxide emissions in

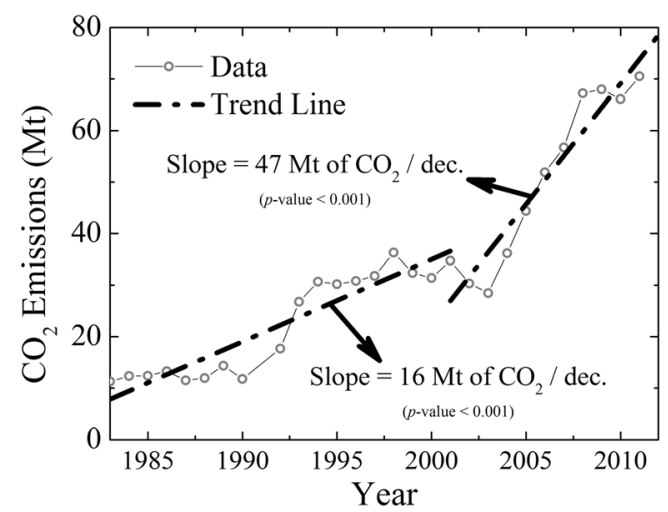

Fig. 15 Relation between carbon dioxide emissions in megatons and temperature extremes

Qatar between 1983 and 2010. The trend value is $16 \mathrm{Mt}$./decade for the period 1983-2000. The trend value has tripled since the turn of the century, which corresponds to the rapid economic and industrial expansion in the nation since 2000 . The increment of carbon dioxide emissions in Qatar since 2000 coincides with the temperature rise over the same period. Comparing Fig. 10 with Fig. 11, the trend values for the daily minimum temperature are larger than the corresponding values for the daily maximum temperature. This observation could be an indication that emissions of greenhouse gases could lead to a more significant increase in the daily minimum temperature. However, further research on this topic is required for a thorough understanding of the asymmetric trends of the maximum and minimum temperatures in Qatar and its dependence on the local level of air pollution. The climatic change in Qatar has been similar to Bahrain, an island nation off the West Coast of Qatar, which has also undergone intense economic development in recent times (Elagib and Abdu 2010). It has been shown that rapid urbanization causes intensified heating of the country, especially in summer.

\section{Conclusions}

The extreme temperature events during a 30 -year period (1983-2012) in Doha, Qatar, were examined in this study. The study provides the most up-to-date analysis of climate change in Doha and neighboring stations within this region. The authors expect that this analysis will fill the gap in the study of climate change over the eastern Arabia Peninsula, where only very limited observational studies are available in the literature. The results showed that a significant warming has occurred in Doha during the studied period, which has occurred at an increasing rate over the last decade. This result is consistent with published studies that have reported global and regional warming trends. For Doha, warming is reflected most in terms of the occurrence of warm days and nights, reduced numbers of cool days and nights, higher minimum 
temperatures in the wet season, and increased frequency of hot days and nights during the dry season. Spatially consistent warming trends were observed in the percentile-based indices for all the cities analyzed within the coastal region. Warming of the temperatures during the wet season and the number of hot days in the dry season were found to be spatially consistent to the east of Doha (Abu Dhabi and Ras Al-Khaimah), whereas to the north (primarily Bushehr), qualitatively similar warming trends were observed in terms of the wet season temperatures.

This detailed weather analysis for Qatar and the evidence for a warming region fill important gaps in the global picture of climate change studies. Further investigations are necessary to understand the effects of local pollution and urbanization on extreme temperatures in Qatar, which will be essential regarding the effective planning of socioeconomic infrastructure.

Acknowledgments This work was supported by the Qatar National Research Fund (a member of the Qatar Foundation) under grants NPRP 5-543-2-220 and 5-671-2-278. The authors wish to acknowledge the help from all the members of Hamad International Airport.

Open Access This article is distributed under the terms of the Creative Commons Attribution 4.0 International License (http:// creativecommons.org/licenses/by/4.0/), which permits unrestricted use, distribution, and reproduction in any medium, provided you give appropriate credit to the original author(s) and the source, provide a link to the Creative Commons license, and indicate if changes were made.

\section{References}

Alexander LV, Zhang X, Peterson TC, Caesar J, Gleason B, Klein Tank AMG, Haylock M, Collins D, Trewin B, Rahimzadeh R, Tagipour A, Rupa Kumar K, Revadekar J, Griffiths G, Vincent L, Stephenson DB, Burn J, Aguilar E, Brunet M, Taylor M, New M, Zhai P, Rusticucci M, Vazquez-Aguirre JL (2006) Global observed changes in daily climate extremes of temperature and precipitation. J Geophys Res-Atmos 111

Almazroui M, Nazrul Islam M, Athar H, Jones P, Rahman MA (2012) Recent climate change in the Arabian Peninsula: annual rainfall and temperature analysis of Saudi Arabia for 1978-2009. Int J Climatol 32:953-966

Almazroui M, Islam MN, Dambul R, Jones P (2014) Trends of temperature extremes in Saudi Arabia. Int J Climatol 34:808-826

AlSarmi S, Washington R (2011) Recent observed climate change over the Arabian Peninsula. J Geophys Res-Atmos 116

AlSarmi SH, Washington R (2014) Changes in climate extremes in the Arabian Peninsula: analysis of daily data. Int J Climatol 34:1329 1345

Aguilar E, Aziz Barry A, Brunet M, Ekang L, Fernandes A, Massoukina M, Mbah J, Mhanda A, do Nascimento DJ, Peterson TC, Thamba Umba O, Tomou M, Zhang X (2009) Changes in temperature and precipitation extremes in western central Africa, Guinea Conakry, and Zimbabwe, 1955-2006. J Geophys Res-Atmos 114

Avila F, Pitman A, Donat M, Alexander L, Abramowitz G (2012) Climate model simulated changes in temperature extremes due to land cover change. J Geophys Res-Atmos 117
Brooks IM, Rogers DP (2000) Aircraft observations of the mean and turbulent structure of a shallow boundary layer over the Persian Gulf. Bound-Layer Meteorol 95:189-210

Brunet M, Saladié M, Jones P, Sigró J, Aguilar E, Moberg A, Lister D, Walther, A, Almarza C (2008) A case-study/guidance on the development of long-term daily adjusted temperature datasets World Meteorological Organization WCDMP-66/WMO-TD-1425, Geneva

Butt N, New M, Lizcano G, Malhi Y (2009) Spatial patterns and recent trends in cloud fraction and cloud-related diffuse radiation in Amazonia. J Geophys Res-Atmos 114

Chung U, Choi J, Yun JI (2004) Urbanization effect on the observed change in mean monthly temperatures between 1951 and 1980 and 1971-2000 in Korea. Clim Chang 66:127-136

Coumou D, Rahmstorf S (2012) A decade of weather extremes. Nat Clim Chang 2:491-496

Deo R, McAlpine C, Syktus J, McGowan H, Phinn S (2007) On Australian heat waves: time series analysis of extreme temperature events in Australia, 1950-2005. In: Proceedings of the International Congress on Modelling and Simulation (MODSIM07). Modelling and Simulation Society of Australia and New Zealand Inc, pp 626635

Donat MG, Alexander LV (2012) The shifting probability distribution of global daytime and night-time temperatures. Geophys Res Lett 39

Donat MG, Peterson TC, Brunet M, King AD, Almazroui M, Kolli RK, Boucherf D, Al Mulla AY, Nour AY, Aly AA, Nada TAA, Semawi MM, Abdullah H, Al Dashti HA, Salhab TG, El Fadli KI, Muftah MK, Eida SD, Badi W, Driouech F, El Rhaz K, Abubaker MJY, Ghulam AS, Erayah AS, Mansour MB, Alabdouli WO, Al Dhanhani JS, Al Shekaili MN (2013) Changes in extreme temperature and precipitation in the Arab region: long-term trends and variability related to ENSO and NAO. Int J Climatol 34:581-592

Easterling DR, Horton B, Jones PD, Peterson TC, Karl TR, Parker DE, Salinger MJ, Razuvayev V, Plummer N, Jamason P, Folland CK (1997) Maximum and minimum temperature trends for the globe. Science 277:364-367

Elagib NA, Abdu ASA (2010) Development of temperatures in the Kingdom of Bahrain from 1947 to 2005. Theor Appl Climatol 101:269-279

Fischer E, Schär C (2010) Consistent geographical patterns of changes in high-impact European heatwaves. Nat Geosci 3:398-403

Frich P, Alexander L, Della-Marta P, Gleason B, Haylock M, Klein Tank A, Peterson T (2002) Observed coherent changes in climatic extremes during the second half of the twentieth century. Clim Res 19:193-212

Hansen J, Ruedy R, Sato M, Lo K (2010) Global surface temperature change. Rev Geophys 48

Nazrul Islam M, Almazroui M, Dambul R, Jones P, Alamoudi A (2014) Long-term changes in seasonal temperature extremes over Saudi Arabia during 1981-2010. Int J Climatol In press

Jones GS, Jones A, Roberts DL, Stott PA, Williams KD (2005) Sensitivity of global-scale climate change attribution results to inclusion of fossil fuel black carbon aerosol. Geophys Res Lett 32

Karl TR, Knight RW, Gallo JP, Peterson TC, Jones PD, Kukla G, Plummer N, Razuvayev V, Lindseay J, Charlson RJ (1993) A new perspective on recent global warming: asymmetric trends of daily maximum and minimum temperature. B Am Meteorol Soc 74: $1007-1023$

Karl TR, Meehl GA, Miller CD, Hassol SJ, Waple AM, Murray WL (2008) In: weather and climate extremes in a changing climate. North America Hawaii Caribbean and U S Pacific Islands, Report by the US Climate Change Science Program, Regions of Focus

Klein Tank AMG, Zwiers FW, Zhang X (2009) Guidelines on Analysis of extremes in a changing climate in support of informed decisions for adaptation. In: Climate Data and Monitoring WCDMP-72/WMOTD-1500, World Meteorological Organization 
Klein Tank AMG, Peterson TC, Quadir DA, Dorji S, Zou X, Tang H, Santhosh K, Joshi UR, Jaswal AK, Kolli RK, Sikder AB, Deshpande NR, Revadekar JV, Yeleuova K, Vandasheva S, Faleyeva M, Gomboluudev P, Budhathoki KP, Hussain A, Afzaal M, Chandrapala L, Anvar H, Amanmurad D, Asanova VS, Jones PD, New MG, Spektorman R (2006) Changes in daily temperature and precipitation extremes in central and south. Asia J Geophys ResAtmos 111

Kostopoulou E, Giannakopoulos C, Hatzaki M, Karali A, Hadjinicolaou P, Lelieveld J, Lange M (2014) Spatio-temporal patterns of recent and future climate extremes in the eastern Mediterranean and middle east region. Nat Hazard Earth Sys 14:1565-1577

Kovats RS, Jendritzky G (2006) Heat-waves and human health climate change and adaptation strategies for human health. Menne B and Ebi KL Editors, Springer, Darmstadt Germany 63-97

Lelieveld J, Hadjinicolaou P, Kostopoulou E, Chenoweth J, El Maayar M, Giannakopoulos C, Hannides C, Lange MA, Tanarhte M, Tyrlis E, Xoplaki E (2012) Climate change and impacts in the Eastern Mediterranean and the Middle East. Clim Chang 114:667-687

Lelieveld J, Hadjinicolaou P, Kostopoulou E, Giannakopoulos C, Pozzer A, Tanarhte M, Tyrlis E (2014) Model projected heat extremes and air pollution in the eastern Mediterranean and Middle East in the twenty-first century. Reg Environ Chang 14:1937-1949

Luber G, McGeehin M (2008) Climate change and extreme heat events American. J Prev Med 35:429-435

Morak S, Hegerl GC, Christidis N (2013) Detectable changes in the frequency of temperature extremes. J Clim 26:1561-1574

Marofi S, Sohrabi MM, Mohammadi K, Sabziparvar AA, Abyaneh HZ (2011) Investigation of meteorological extreme events over coastal regions of Iran. Theor Appl Climatol 103:401-412

Martens W (1998) Health impacts of climate change and ozone depletion: an ecoepidemiologic modeling approach. Environ Health Persp 106: 241

Meehl GA, Tebaldi C (2004) More intense, more frequent, and longer lasting heat waves in the 21st century. Science 305:994-997

Nasrallah HA, Nieplova E, Ramadan E (2004) Warm season extreme temperature events in Kuwait. J Arid Environ 56:357-371

Parmesan C, Root TL, Willig MR (2000) Impacts of extreme weather and climate on terrestrial biota. B Am Meteorol Soc 81:443-450

Peterson TC, Manton MJ (2008) Monitoring changes in climate extremes: a tale of international collaboration. B Am Meteorol Soc 89:1266-1271

Price C, Michaelides S, Pashiardis S, Alpert P (1999) Long term changes in diurnal temperature range in Cyprus. Atmos Res 51:85-98

Qureshi S, Khan N (1994) Estimation of climatic transition in Riyadh (Saudi Arabia) in global warming perspectives. GeoJournal 33:423432

Rahimzadeh F, Asgari A, Fattahi E (2009) Variability of extreme temperature and precipitation in Iran during recent decades. Int $\mathrm{J}$ Climatol 29:329-343

Seneviratne SI, Donat MG, Mueller B, Alexander LV (2014) No pause in the increase of hot temperature extremes. Nat Clim Chang 4:161163

Sen PK (1968) Estimates of the regression coefficient based on Kendall's tau. J Am Stat Assoc 63:1379-1389

Shi JJ, Chang SW, Holt TR, Hogan TF, Westphal DL (2004) A meteorological reanalysis for the 1991 Gulf War. Mon Weather Rev 132: 623-640
Singha A, Sadr R (2012) Characteristics of surface layer turbulence in coastal area of Qatar. Environ Fluid Mech 12:515-531

Solomon S (2007) Climate change 2007-the physical science basis: working group I contribution to the fourth assessment report of the IPCC vol 4. Cambridge University Press

Trenberth KE (2012) Framing the way to relate climate extremes to climate change. Clim Chang 115:283-290

Unger J (1999) Comparisons of urban and rural bioclimatological conditions in the case of a central-European city. Int J Biometeorol 43: 139-144

Vincent LA, Peterson TC, Barros VR, Marino MB, Rusticucci M, Carrasco G, Ramirez E, Alves LM, Ambrizzi T, Berlato MA, Grimm AM, Marengo JA, Molion L, Moncunill DF, REbello E, Anunciação YMT, Quintana J, Santos JL, Beaz J, Coronel G, Garcia J, Trebejo I, BidegainM HMR, Karoly D (2005) Observed trends in indices of daily temperature extremes in South America 1960-2000. J Clim 18:5011-5023

Wang XL (2008) Accounting for autocorrelation in detecting mean shifts in climate data series using the penalized maximal $t$ - or $F$ - test. J Appl Meteorol Clim 47:2423-2444

Wang XL, Wen QH, Wu Y (2008) Penalized maximal t test for detecting undocumented mean change in climate data series. J Appl Meteorol Clim 46:916-931

Wang XL, Feng Y (2010) Climate Research Division Atmospheric Science and Technology Directorate Science and Technology Branch, Environment Canada Toronto, Ontario, Canada http:// etccdipacificclimateorg/RHtest/RHtestsV3_UserManualdoc

Webster PJ, Moore AM, Loschnigg JP, Leben RR (1999) Coupled oceanatmosphere dynamics in the Indian Ocean during 1997-98. Nature 401:356-360

World Bank Group, World Development Indicators - September 2014 Edition (2014a) Total population population density [data file] retrieved from http://databankworldbank.org/data/download/archive/ WDI_excel_2014_09zip retrieved 18th October 2014, World Bank Publications

World Bank Group, World Development Indicators - September 2014 Edition (2014b) Energy use (kt of oil equivalent) [data file] retrieved from http://databankworldbank.org/data/download/archive/WDI excel_2014 09zip retrieved 18th October 2014, World Bank Publications

World Bank Group, World Development Indicators - September 2014 Edition (2014c) $\mathrm{CO}_{2}$ Emissions nitrous oxide emissions [data file] retrieved from http://databankworldbank.org/data/download/ archive/WDI excel 2014 09zip retrieved 18th October 2014, World Bank Publications

Yu L, Rienecker MM (1999) Mechanisms for the Indian Ocean warming during the 1997-98 El Nino. Geophys Res Lett 26:735-738

Zhai P, Pan X (2003) Trends in temperature extremes during 1951-1999 in China. Geophys Res Lett 30

Zhang X et al. (2005) Trends in Middle East climate extreme indices from 1950 to 2003. J Geophys Res-Atmos 110

Zhang X, Alexander LV, Hegerl GC, Jones P, Klein Tank TA, Peterson C, Trewin B, Zwiers FW (2011) Indices for monitoring changes in extremes based on daily temperature and precipitation data. Wiley Interdiscip Rev Clim Chang 2:851-870

Zwiers FW, Zhang X, Feng Y (2011) Anthropogenic influence on long return period daily temperature extremes at regional scales. J Clim 24:881-892 